\title{
Use of combination of accelerator-based ion-beam analysis techniques to the investigation of the corrosion behavior of CoCrMo alloy
}

\author{
F. Noli ${ }^{\text {a,* }}$, P. Misaelides ${ }^{\text {a }}$, A. Lagoyannis ${ }^{\mathrm{b}}$, L. Pichon ${ }^{\mathrm{c}}$, O. Ozturk ${ }^{\mathrm{d}}$ \\ a Department of Chemistry, Aristotle University, GR-54124 Thessaloniki, Greece \\ ${ }^{\mathrm{b}}$ Tandem Accelerator Laboratory, Nuclear Physics Institute, NCSR Demokritos, GR-15310 Aghia Paraskevi, Attiki, Greece \\ 'Institut P' UPR 3346 Université de Poitiers, CNRS F-86960 Futuroscope, Cedex, France \\ ${ }^{\mathrm{d}}$ Department of Physics, Izmir Institute of Technology, Gulbahce-Urla, 35430 Izmir, Turkey
}

\section{A R T I C L E I N F O}

\section{Article history:}

Received 30 September 2013

Received in revised form 19 November 2013

Accepted 20 November 2013

Available online 10 February 2014

\section{Keywords:}

Plasma nitridation-oxidation

RBS

NRA

SEM

Corrosion

CoCrMo alloy

\begin{abstract}
A B S T R A C T
Nuclear Reaction Analysis - NRA in combination with d-RBS $\left(E_{\mathrm{d}}: 1.35 \mathrm{MeV}\right)$ was applied in order to investigate the corrosion behavior of CoCrMo alloy. The corrosion resistance of the alloy was compared to that of modified CoCrMo samples by several techniques as plasma nitriding and oxidizing at moderate temperature $\left(\sim 400^{\circ} \mathrm{C}\right)$. Electrochemical techniques in simulated body fluid $0.9 \% \mathrm{NaCl}\left(37^{\circ} \mathrm{C}\right)$ were applied in order to accelerate the corrosion process. The nitrogen depth distribution before and after the corrosion was determined using the ${ }^{14} \mathrm{~N}(\mathrm{~d}, \boldsymbol{\alpha}){ }^{12} \mathrm{C}$ and the ${ }^{14} \mathrm{~N}(\mathrm{~d}, \mathrm{p}){ }^{15} \mathrm{~N}$ nuclear reactions whereas the oxygen by the ${ }^{16} \mathrm{O}(\mathrm{d}, \mathrm{p})^{17} \mathrm{O}$. The surface morphology and microstructure was investigated using microscopy techniques. It was found that surface treatments produce thick nitrided layers $(5-6 \mu \mathrm{m})$ consisting of a supersaturated nitrogen solution (nitrogen concentration is $\sim 30$ at.\%) in the matrix (expanded phase $\gamma_{\mathrm{N}}$ ) and a thin oxygen solution $(0.3 \mu \mathrm{m})$. The samples subjected to plasma nitridation and oxidation exhibited the lowest deterioration and better resistance to corrosion compared to the single nitrided or single oxidized and the untreated material. This could be attributed to the modified surface region with the high nitrogen content and the presence of oxygen.
\end{abstract}

(c) 2014 Elsevier B.V. All rights reserved.

\section{Introduction}

CoCrMo alloys, due to their excellent mechanical properties and corrosion resistance have been widely used in orthopaedic prosthesis. However, their wear and corrosion stability are of great concern during the last years [1-3]. Literature studies showed that the released of metal ions (e.g. $\mathrm{Co}, \mathrm{Cr}, \mathrm{Mo}$ ) may interact with the neural system, influence bone mineralization or be carcinogenic [4-7]. The long term durability of the implants relies on the control of their corrosion resistance and wear behavior. Therefore, the increase of their lifetime through development of a corrosion- and wear-resistant biocompatible surface layer is of special importance.

Recent studies indicated that plasma nitriding (PN) and plasmabased ion implantation (PBII) at moderate temperatures $\left(\sim 400^{\circ} \mathrm{C}\right)$ can considerably improve the wear and fatigue resistance of metallic alloys with austenitic structure (e.g. steels, Ni-based alloys, $\mathrm{CoCr}$ alloys with a face cubic centred FCC $\gamma_{N}$ phase). Such nitriding leads to the formation of thick nitrided layers (of few $\mu \mathrm{m}$ after few hours of treatment), consisting of a supersaturated nitrogen solution in

\footnotetext{
* Corresponding author. Tel.: +30 2310 997997; fax: +30 2310997753.

E-mail address: noli@chem.auth.gr (F. Noli).
}

the a $\gamma_{N}$ matrix, usually called expanded S-phase or a $\gamma_{N}[7-10]$. These techniques are "3D" processes allowing a workpiece of complex shape to be treated from all sides. The treatments were also shown to improve the tribological and corrosion properties of the modified material surfaces.

The objective of this work was the investigation of the effect of plasma assisted nitriding or oxidizing on the corrosion and mechanical properties of CoCrMo alloy for biomedical applications using a combination of accelerator-based ion-beam analysis techniques.

\section{Experimental details}

\subsection{Samples preparation}

The investigated alloy was a commercial medical grade CoCrMo substrate (ISO 5832-12) with composition $\mathrm{Cr}$ (27.66 wt.\%), Mo (5.60 wt.\%), Al (0.01 wt.\%), Ti (0.01 wt.\%), C (0.048 wt.\%), Zr (0.01 wt.\%), Fe (0.08 wt.\%) and Co (ca. 65 wt.\%).

Three sets of samples were prepared in a R.F. plasma assisted thermal treatment reactor previously described $[11,12]$. The first set $(\mathrm{CoCrMo}+\mathrm{N})$ was nitrided at $395{ }^{\circ} \mathrm{C}$ for $150 \mathrm{~min}$, in $8 \mathrm{~Pa}$ of 
Table 1

Chemical composition of the investigated CoCrMo samples.

\begin{tabular}{|c|c|c|c|c|c|c|c|c|}
\hline Sample & Treatment & $T\left({ }^{\circ} \mathrm{C}\right)$ & Thickness $(\mu \mathrm{m})$ & Co (wt.\%) & $\mathrm{Cr}(\mathrm{wt} . \%)$ & Mo (wt.\%) & $\mathrm{O}$ (wt.\%) & $\mathrm{N}$ (wt.\%) \\
\hline $\mathrm{CoCrMo}+\mathrm{N}$ & Nitridation & 395 & 4.6 & 40 & 20 & 6 & - & 34 \\
\hline $\mathrm{CoCrMo}+\mathrm{O}$ & Oxidation & 400 & 0.3 & 54 & 20 & 2 & 34 & - \\
\hline $\mathrm{CoCrMo}^{+}$ & Nitridation+ & 395 and & 6.0 & 40 & 20 & 2 & 15 & 23 \\
\hline $\mathrm{N}+\mathrm{O}$ & Oxidation & 400 & & & & & & \\
\hline
\end{tabular}

$\mathrm{N}_{2}$ (60 vol.\%) and $\mathrm{H}_{2}$ (40 vol.\%), with R.F. power of $700 \mathrm{~W}$. The second set $(\mathrm{CoCrMo}+\mathrm{O})$ was oxidized at $400{ }^{\circ} \mathrm{C}$, for $120 \mathrm{~min}$, in $8 \mathrm{~Pa}$ of $\mathrm{O}_{2}$, with R.F. power of $700 \mathrm{~W}$. The third set $(\mathrm{CoCrMo}+\mathrm{N}+\mathrm{O})$ is composed of initially nitrided samples (like the first set) being oxidized afterward like the second set.

\subsection{Samples characterization}

The structure, the composition and the surface morphology of the materials were investigated by X-ray Diffraction (XRD), Glow Discharge Optical Emission Spectroscopy (GDOES), X-ray Photoelectron Spectroscopy (XPS). Micro-hardness and wear tests were also performed to study the modifications of the mechanical and wear resistance (results to be published).

The thickness and the chemical composition of the modified layers of the materials were investigated, prior and after the corrosion tests, by Rutherford Backscattering Spectrometry (RBS) and Nuclear Reaction Analysis (NRA) using $1.35 \mathrm{MeV}$ deuteron beams at the 5.5 MV Tandem Accelerator of the NCSR Demokritos (Athens, Greece). For the determination of the nitrogen and oxygen content of the samples the ${ }^{14} \mathrm{~N}(\mathrm{~d}, \mathrm{p}){ }^{15} \mathrm{~N},{ }^{14} \mathrm{~N}(\mathrm{~d}, \alpha){ }^{12} \mathrm{C}$ and ${ }^{16} \mathrm{O}(\mathrm{d}, \mathrm{p}){ }^{17} \mathrm{O}$ nuclear reactions were utilized [13]. The beam spot size was $1.5 \times 1.5 \mathrm{~mm}^{2}$ and the overall uncertainty of the determination was estimated to be ca. 5\%. The analysis of the RBS and NRA data was performed by the SIMNRA code $[14,15]$ as well as for the simulation of nitrogen, oxygen and carbon the cross section data of S. Pellegrino, A. Gurbich and M. Kokkoris were taken into account respectively [16-19].

Examinations of the samples by SEM/EDS were performed using a JEOL JSM 840A electron microscope equipped with an energy - dispersive X-ray (EDS) INCA micro-analytical system (accelerating voltage $20 \mathrm{kV}$, probe current $45 \mathrm{nA}$ and counting time $60 \mathrm{~s}$, with ZAF correction being provided on-line). The samples were coated before the examination with carbon, using a JEOL JEE-4X vacuum evaporator.

\subsection{Corrosion tests}

The investigation of the corrosion behavior of the samples was performed in an argon aerated $\mathrm{NaCl} 0.9 \%$ solution by means of potentiodynamic and cyclic voltammetric techniques according to ASTM Designation G5-82 [20]. The tests were undertaken at room temperature in an AUTOLAB Potentio-Galvanostat (ECO CHEMIE, Netherlands) interfaced with a computer and recorder. A conventional three-electrode cell (EG\&G PARR model) was used for all measurements. The cell was equipped with a saturated calomel reference electrode, a graphite auxiliary electrode and a holder leaving only the one side of the specimen exposed to the corroding medium. In all cases the electrolyte volume was $800 \mathrm{ml}$ and the sample surface which was in contact with the testing solution $1 \mathrm{~cm}^{2}$. The open circuit potential or corrosion potential $E_{\text {corr }}$ was recorded after 30 min stabilization whereas rapid $(50 \mathrm{~V} /$ $\mathrm{h})$ and slow scan rates $(0.6 \mathrm{~V} / \mathrm{h})$ were used. The potential investigated region was $-1000 / E_{\text {corr }} /+1250 \mathrm{mV}$.

\section{Results}

Table 1 gives the average chemical composition and the thickness of the main modified zone obtained by RBS and NRA using
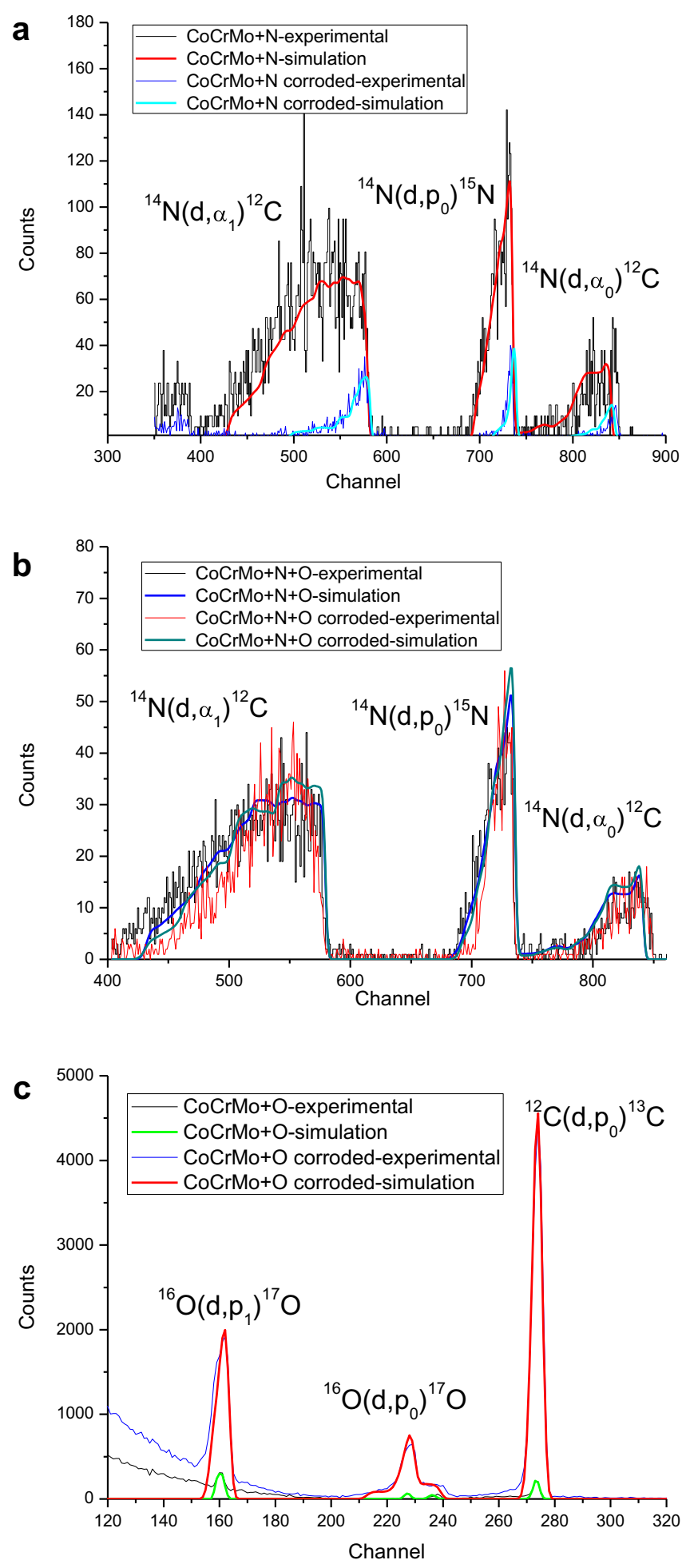

Fig. 1. (a and b) Nitrogen determination, (c) oxygen and carbon determination, by NRA before and after the corrosion investigation. 


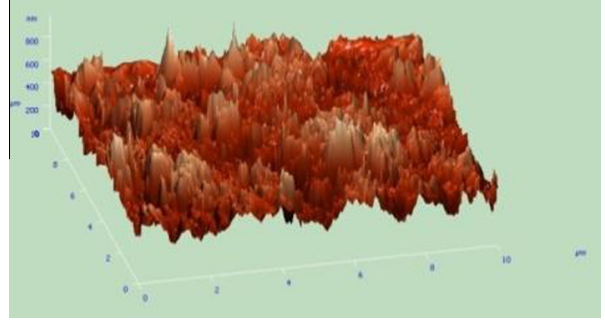

Fig. 2. AFM image of the corroded CoCrMo sample.

1.35 MeV deuterons as projectiles. The concentrations as well as the depth distribution of the constituents of the modified CoCrMo layers are in agreement with the corresponding values obtained using GDOES.

Fig. 1( $a$ and $b$ ) present the nitrogen profiles of the single (nitrided) and doubly treated (nitrided and oxidized)) sample according the corresponding simulations. Fig. 1(c) presents the characteristic proton peaks of oxygen $\left(\mathrm{p}_{0}\right.$ and $\left.\mathrm{p}_{1}\right)$ whereas the carbon $(d, p)$ peak is also observed. The nitridation of the samples leads to the formation of thin (few nm) surface oxy-nitrided layer mainly consisting of $\mathrm{Co}$ (almost no $\mathrm{Cr}$ ) followed by a thick nitrided layer (max. N-content $\sim 25 \%$ ) ranging over $4.6 \mu \mathrm{m}$. The oxidation of the alloy leads to the formation of a ca. $60 \mathrm{~nm}$ surface layer mainly consisting of cobalt oxide. No significant modification was observed underneath. The combination of nitridation followed by oxidation resulted in a thick (ca. $250 \mathrm{~nm}$ ) layer mainly consisting of cobalt oxide (the $\mathrm{Cr}$ presence is rather limited). The nitrogen content of the nitrided layer below the oxide was slightly lower of a few percent indicating nitrogen diffusion to deeper layers (5-6 $\mu \mathrm{m}$ ) during the oxidizing treatment. No oxygen was found in regions deeper than $300 \mathrm{~nm}$. It has to be pointed out that carbon was detected (ca. 6\%) in the case of the nitrided or oxidized samples at a depth of ca. $100 \mathrm{~nm}$ whereas on the initial material its content was low (ca. 1\%) fact connected to the treatment procedure (nitridation and oxidation) [12].

The XRD and GIXRD investigation showed in the case of CoC$\mathrm{rMo}+\mathrm{N}$ sample the formation of a $\gamma_{\mathrm{N}}$ expanded austenite phase $[11,12]$. The formation of a $\gamma_{N}$ expanded austenite phase was also observed in the case of the $\mathrm{CoCrMo}+\mathrm{N}+\mathrm{O}$ sample. The presence of $\mathrm{CrN}$ and $\mathrm{CoO}$ was additionally confirmed by XPS measurements. The study of the CoCrMo + O samples showed the formation of the corresponding metal oxides.

The SEM images of the polished initial as well as of the nitrided, oxidized and nitrided + oxidized CoCrMo samples showed that the surface alloy is quite scratchy. In the case of the modified samples and especially on the surface of the nitrided sample plasticity defects and intergranular cracks with morphology of unevenly distributed snowflake-like grains were observed. The distribution is much more uniform in the case of the nitrided + oxidized sample. The EDS analysis was carried out on large areas as well as on the grains. Based on the EDS results, the $\mathrm{N}$ concentration values ranged from ca. 28 to 31 at.\% in the nitrided layer.

After nitridation a significant improvement of the Vickers hardness (HV) was observed compared to the initial material, whereas in the case of the CoCrMo + O sample no improvement was observed because of the limited thickness of the oxide layer. The hardness of $1100 \mathrm{HV}(\sim 11 \mathrm{GPa})$ observed using low loads ( $25 \mathrm{~g}$ ) for the CoCrMo + N sample (ca. 500 HV is the value for the initial material) is more or less representative of the nitride layer. With increasing the load the measured hardness decreased because of the bulk influence. The behavior of the CoCrMo $+\mathrm{N}+\mathrm{O}$ sample is similar although the roughness of the sample surface makes difficult the accurate evaluation of the measurements. Based on AFM measurements the mean roughness value $\left(1 \times 1 \mu \mathrm{m}^{2}\right)$ varied from
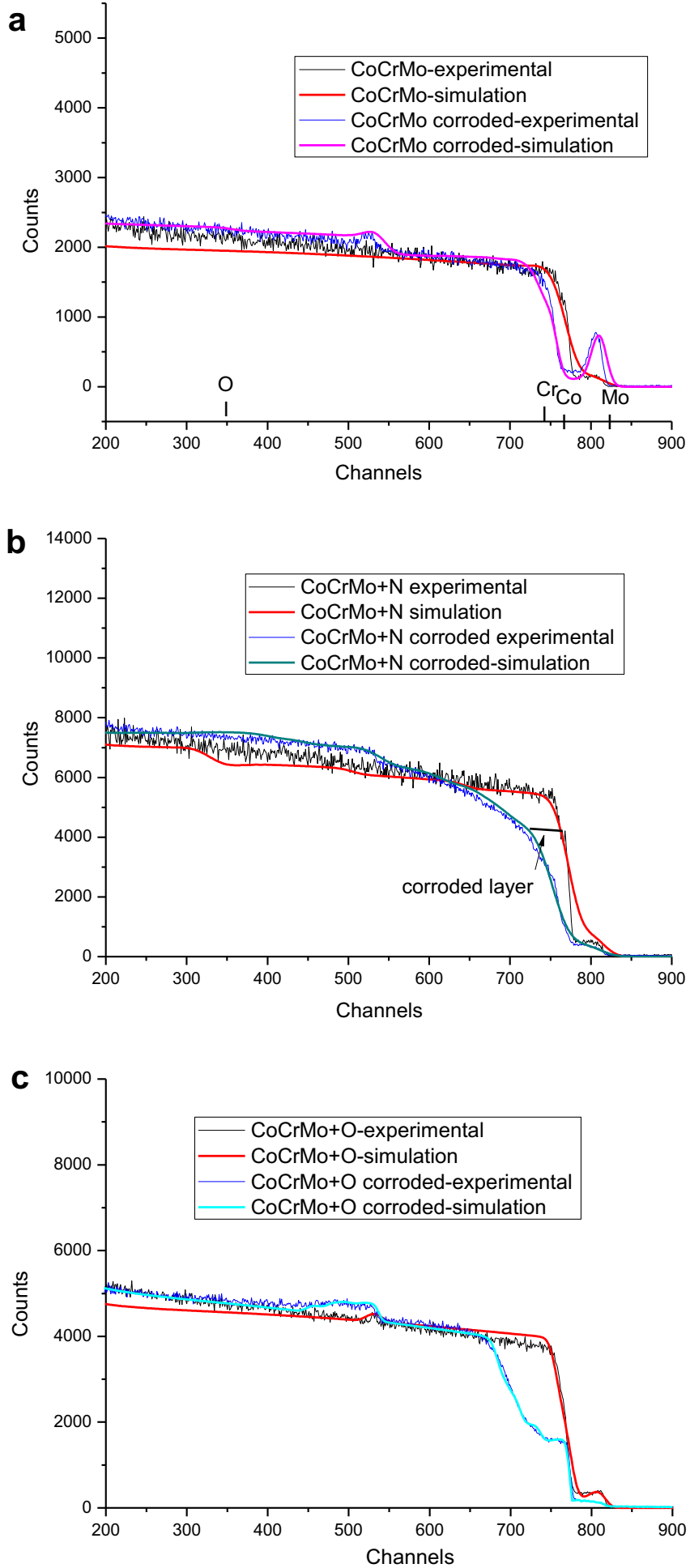

Fig. 3. RBS spectra of the non-corroded and corroded CoCrMo, CoCrMo $+\mathrm{N}$ and CoCrMo + O samples.

ca. $5 \mathrm{~nm}$ for the initial material to ca. 30,40 and $50 \mathrm{~nm}$ for the oxidized, nitrided and nitrided + oxidized sample respectively.

The corrosion investigation showed that the modified samples were stable. The modification of the surface layers of the samples did not affect the corrosion resistance of the CoCrMo substrate. The doubly treated (nitrided and oxidized) samples exhibited slight higher corrosion resistance than the single nitrided ones likely due to the formation of thicker modified surface layers. 

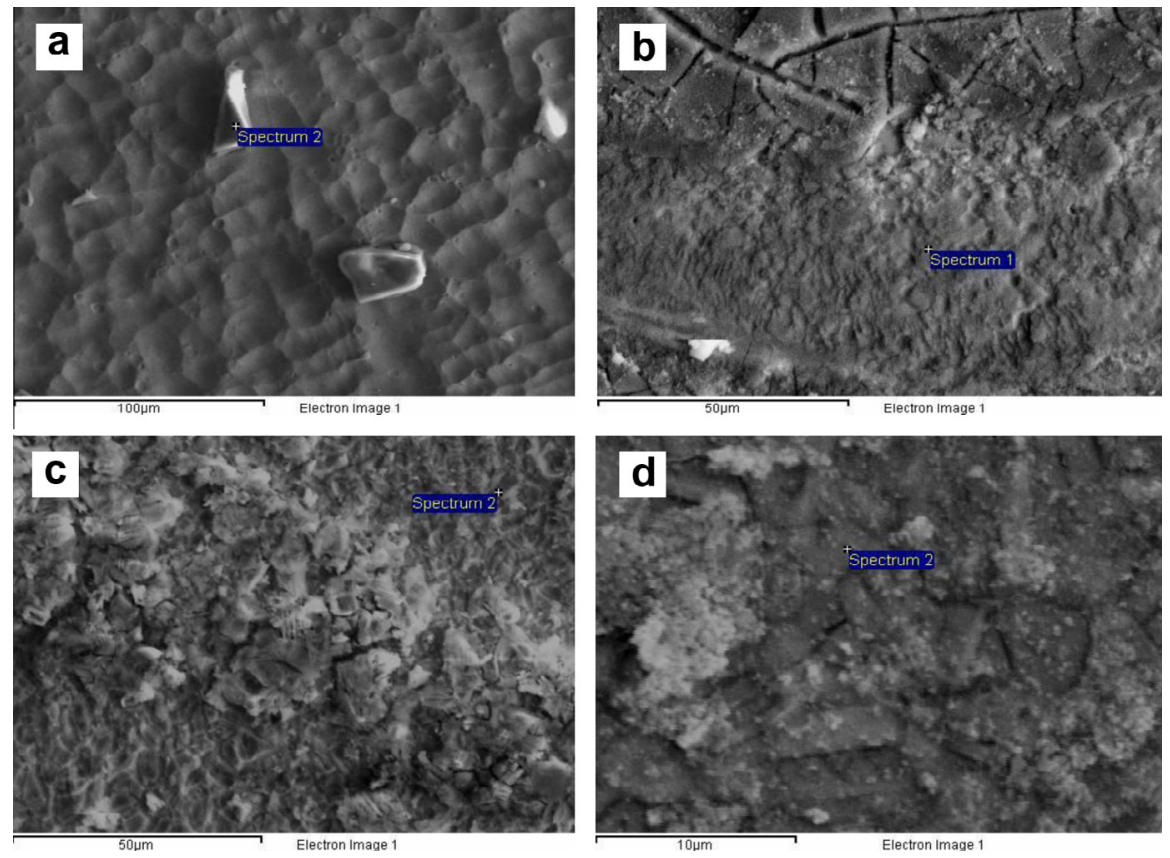

Fig. 4. SEM images of the corroded CoCrMo, CoCrMo $+\mathrm{N}, \mathrm{CoCrMo}+\mathrm{O}$ and $\mathrm{CoCrMo}+\mathrm{N}+\mathrm{O}$ samples.

The oxidized samples presented a lower corrosion resistance but still higher than the non-modified material due to the limited thickness of the surface oxide. The thickness of the nitrided layer remained unchanged during the corrosion treatment only in the case of the double treatment. The roughness of the surface significantly increased, especially in the case of the initial material (3 up to 10 times), and showed a large variation in different points as it is demonstrated by the AFM investigation (see Fig. 2). The modified samples exhibited nobler values of the $E_{\text {cor }}, E_{\text {pit }}$ and $E_{\text {rep }}$ (corrosion, pitting and repassivation potentials) and broadened region of passivity. The values of the maximum current $\boldsymbol{i}_{\max }$ decreased rapidly in the case of the nitrided sample (30 and $20 \mathrm{~mA}$ for the single and double treatment respectively) as well as for the oxidized sample was 35 and for the initial sample $40 \mathrm{~mA}$.

In Fig. 3(a) the corresponding RBS spectra of the initial CoCrMo alloy before and after the corrosion investigation are presented. From the deduced profiles the corrosion is estimated to proceed to a depth up to $750 \mathrm{~nm}$. One can observe in the case of the corroded sample the intense Mo peak (channel 800) and a shift of the bulk band indicating an extensive Co dissolution. The cobalt dissolution was also verified by the EDS measurements where the Co concentration was significantly decreased (ca. 3\%) after the corrosion in comparison with the modified samples where the dissolution was lower (Co concentration ca. 15\%). Instrumental Neutron Activation Analysis (INAA), applied in order to get information on the $\mathrm{Co}, \mathrm{Cr}$ and Mo released by the CoCrMo alloy samples during the corrosion testing, showed that the Co release in the case of the initial material was one order of magnitude higher than in the case of the modified materials. Literature results also report this phenomenon indicating incomplete formation of the protective chromium oxide $[3,4]$.

The corresponding RBS spectra of the nitrided and oxidized samples illustrated in Fig. 3(b and c) presented a different depict after the electrochemical study. The corrosion seems to proceed on the surface layers of thickness 300 and $600 \mathrm{~nm}$ respectively without affecting the bulk. In all the corroded samples the oxygen and especially the carbon peaks were found to increase. The NRA data also proved that the $\mathrm{CoCrMo}+\mathrm{N}+\mathrm{O}$ samples showed the lowest deterioration and the best corrosion resistance. This is most probably connected with the nitrogen depth distribution which was only slightly affected by the corrosion treatment whereas the CoCrMo $+\mathrm{N}$ sample is on the contrary intensively affected (see Fig. 1(a and b)).

Fig. 4(a) shows the surface morphology of the CoCrMo sample after the corrosion attack. The surface seems inhomogeneous with pores and defects. EDS analysis on these formations showed large variation of the Co concentration indicating that the corrosion preferentially occurred in these sites. In the case of the modified samples (Fig. 4(b and c)) flakes and cracks were observed, in lower degree on the nitrided + oxidized sample, whereas the EDS data showed reduced dissolution of $\mathrm{Co}$ and $\mathrm{Cr}$, indicating higher stability of the treated surface against corrosion.

The RBS, NRA and SEM-EDS data could explain the observation that among the investigated samples those subjected to nitridation + oxidation showed the best corrosion resistance. Their better behavior could be attributed to the presence of oxygen in the nitrided surface region, which seems to stabilize the nitrogen layer and to inhibit the nitrogen dissolution. The beneficial effect of nitrogen on the corrosion of several alloys has been widely reported in the literature and could be associated to structural effects (formation of an amorphous layer) but mainly to chemical reasons [21].

\section{Conclusions}

The results of this work showed that it is possible to improve the corrosion resistance and control the properties of the CoCrMo alloys by surface modification using plasma assisted nitridation and oxidation. Among the investigated samples those subjected to double treatment (nitridation + oxidation) showed the best corrosion resistance. This could be attributed to the modified surface region with the high nitrogen content and the presence of oxygen which seems to stabilize the nitride layer.

The accelerator-based ion-beam analysis techniques can considerably contribute to the investigation and improvement of the properties of metallic alloys for biomedical applications. 


\section{Acknowledgements}

The assistance of the SEM and AFM staff at the Faculty of Sciences of the University of Thessaloniki is thankfully acknowledged. Work performed within the frame of the IAEA-CRP 1576 "Micro-analytical Techniques Based on Nuclear Spectrometry for Environmental Monitoring and Material Studies" (Research Agreement 15967: Use of Combination of Accelerator-Based Ion-Beam Analysis Techniques to the Study of Materials for Biomedical Applications).

\section{References}

[1] N. Maruyama, H. Kawasaki, A. Yamamoto, S. Hiromoto, H. Imai, T. Hanawa, Mater. Trans. 46 (7) (2005) 1588.

[2] A. Bazzoni, S. Mischler, N. Espallargs, Tribol. Lett. (2012) 508.

[3] J. Lutz, C. Diaz c, J.A. Garcia, C. Blawert, S. Mandl, Surf. Coat. Technol. 205 (2011) 3043.

[4] O. Ozturk, U. Turkan, A. Eroglu, Surf. Coat. Technol. 200 (2006) 5687.

[5] D. Bunea, D. Bojin, S. Zamfir, F. Miculescu, M. Miculescu, Eur. Cells Mater. 5 (Suppl. 1) (2003) 53.

[6] S. Virtanena, I. Milošev, E. Gomez-Barenna, R. Trebše, J. Saloe, Y.T. Konntinen, Acta Biomater. 4 (2008) 468.

[7] G. Bellefontaine, The corrosion of CoCrMo alloys for biomedical applications, Thesis of Master of Research, School of Metallurgy and Materials, University of Birmingham, January 2010.
[8] L. Pichon, J. Cormier, A. Delemy, S. Chollet, P. Villechaise, J.B. Dubois, C. Templier, J. Mater. Sci. 48 (4) (2013) 1585.

[9] R.M. Oliveira, C.B. Mello, G. Silva, J.A.N. Gonçalves, M. Ueda, L. Pichon, Surf. Coat. Technol. 205 (2011) 111.

[10] H. Dong, Internet Mater. Rev. 55 (2010) 65.

[11] O. Ozturk, S. Okur, L. Pichon, M.O. Liedke, J.P. Riviere, Surf. Coat. Technol. 205 (2011) 280.

[12] L. Pichon, S. Okur, O. Ozturk, J.P. Riviere, M. Drouetet, Surf. Coat. Technol. 204 (2010) 2913.

[13] F. Noli, P. Misaelides, A. Lagoyannis, A. Akbari, Nucl. Instrum. Methods Phys. Res., Sect. B 269 (2011) 3226.

[14] M. Mayer, SIMNRA User’s Guide 6.0, Max Planck Institut für Plasmaphysik, Garching, 2006.

[15] Ion-Beam Analysis Nuclear Data Library, <http://amdu1.iaea.org/ibandl/>.

[16] S. Pellegrino, L. Beck, Ph. Trouslard, Nucl. Instrum. Methods Phys. Res., Sect. B 219-220 (2004) 140.

[17] A. Gurbich, S. Molodtsov, Nucl. Instrum. Methods Phys. Res., Sect. B 266 (2008) 1206.

[18] A. Gurbich, S. Molodtsov, Nucl. Instrum. Methods Phys. Res., Sect. B 226 (2004) 637.

[19] M. Kokkoris, P. Misaelides, K. Kossionidis, et al., Nucl. Instrum. Methods Phys. Res., Sect. B 249 (2006) 77.

[20] R. Baboian (Ed.), Corrosion Tests and Standards, American Society for Testing and Materials, Philadelphia, 1995.

[21] F. Noli, P. Misaelides, E. Pavlidou, A. Lagoyannis, J.P. Riviere, Surf. Coat. Technol. 204 (2011) 2913. 